\title{
Synthesis of Porous Crystalline Doped Titania Photocatalysts \\ Using Modified Precursor Strategy
}

\author{
Michal Marszewski, ${ }^{\dagger}$ Jowita Marszewska $^{\dagger}{ }^{\text {Svitlana Pylypenko }},{ }^{\dagger}$ Mietek Jaroniec ${ }^{\dagger *}$ \\ ${ }^{\dagger}$ Department of Chemistry and Biochemistry, Kent State University, Kent, $\mathrm{OH} 44242$, USA \\ ${ }^{*}$ Department of Chemistry, Colorado School of Mines, Golden, CO 80401, USA \\ * Corresponding author: Mietek Jaroniec, Department of Chemistry and Biochemistry, Kent State \\ University, Kent, OH 44242, USA; tel: +1 (330) 672-2032; fax: +1 (330) 672-3816, e-mail: \\ jaroniec@kent.edu
}

Table S1. Characterization of the samples prepared from TIPO modified with: formic, acetic, chloroacetic, oxalic, benzoic, phthalic, isophthalic, and trimesic acids.*

\begin{tabular}{ccccc}
\hline Acid & $\begin{array}{c}\text { TIPO:acid } \\
\text { ratio }\end{array}$ & $\begin{array}{c}\text { Carbon } \\
\text { content } \\
(\mathbf{w t} \mathbf{\%})\end{array}$ & $\begin{array}{c}\text { Specific } \\
\text { surface area } \\
\left(\mathbf{m}^{\mathbf{2}} \mathbf{g}^{\mathbf{- 1}}\right)\end{array}$ & $\begin{array}{c}\text { Total pore } \\
\text { volume } \\
\left(\mathbf{c m}^{\mathbf{3}} \mathbf{g}^{\mathbf{- 1}}\right)\end{array}$ \\
\hline Formic & $1: 2$ & 1.4 & 4 & 0.03 \\
Acetic & $1: 2$ & 3.9 & 19 & 0.04 \\
Chloroacetic & $1: 2$ & 7.6 & 33 & 0.20 \\
Oxalic & $1: 2$ & 0.4 & 11 & 0.04 \\
Benzoic & $1: 2$ & 2.1 & 11 & 0.09 \\
Phthalic $^{\mathrm{a}}$ & $1: 2$ & 16.3 & 66 & 0.18 \\
Isophthalic $^{\mathrm{b}}$ & $1: 2$ & 36.3 & 89 & 0.15 \\
Trimesic $^{\mathrm{b}}$ & $1: 2$ & 52.7 & 99 & 0.11 \\
\hline
\end{tabular}

*Notation: TIPO denotes titanium isopropoxide. Carbon content was calculated based on thermogravimetric profile recorded in air. Specific surface area was calculated based on lowtemperature nitrogen adsorption using the Brunauer-Emmett-Teller method. Total pore volume was calculated based on the nitrogen amount adsorbed at the relative pressure $\approx 0.99$. ${ }^{\text {a }}$ phthalic acid was prepared from phthalic anhydride by hydrolysis before TIPO addition; ${ }^{\mathrm{b}}$ isophthalic and trimesic acids dissolve poorly in ethanol, but precipitation of the product (modified TIPO) from the solution is assumed to have pushed the reaction to completion. 


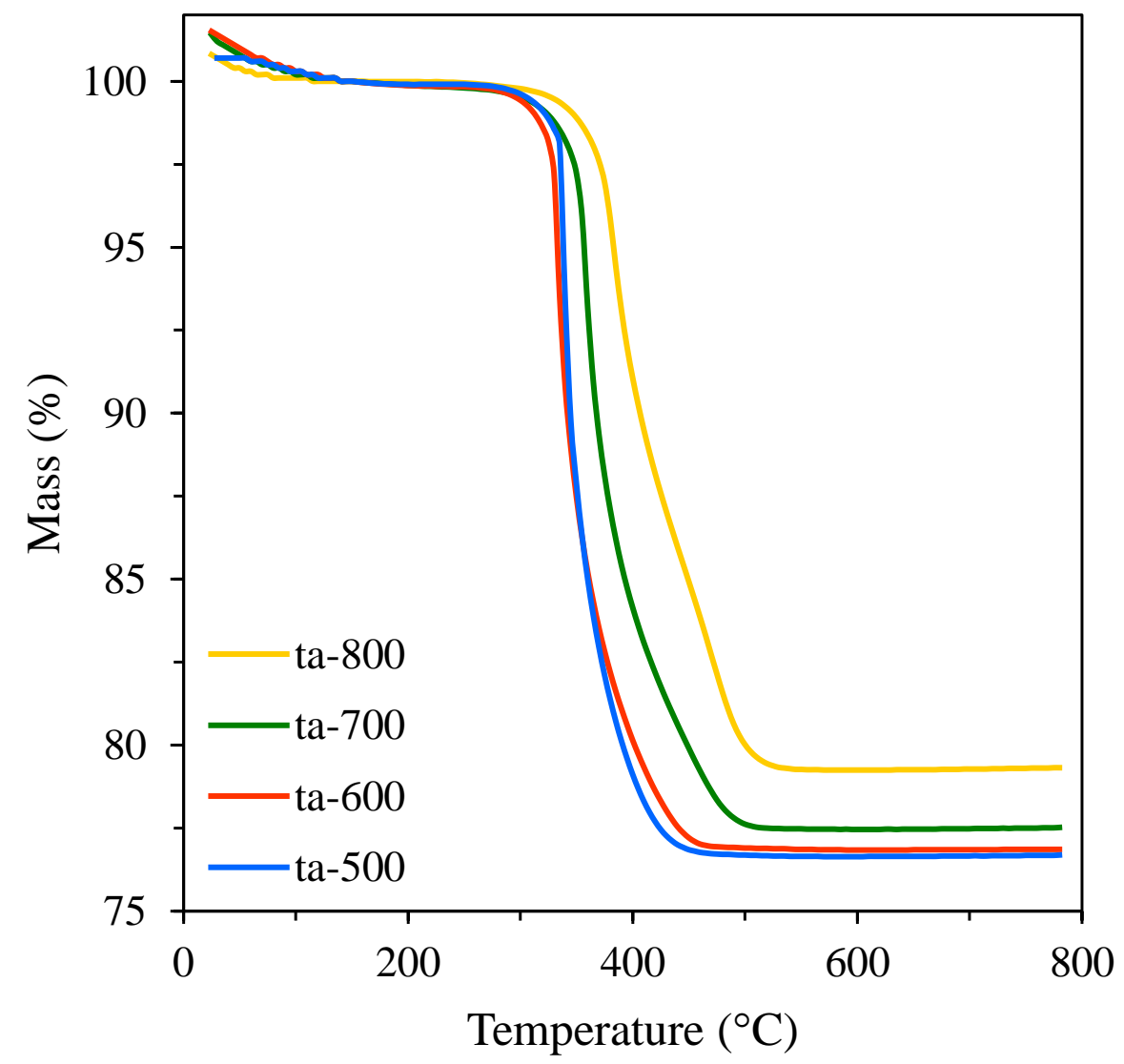

Figure S1. Thermogravimetric curves for the carbon-titania composites prepared from $\mathrm{TiO}(\mathrm{acac})_{2}$. Each TG run was done in air. $100 \%$ mass is set for the outgassed sample, i.e., at $150{ }^{\circ} \mathrm{C}$. 


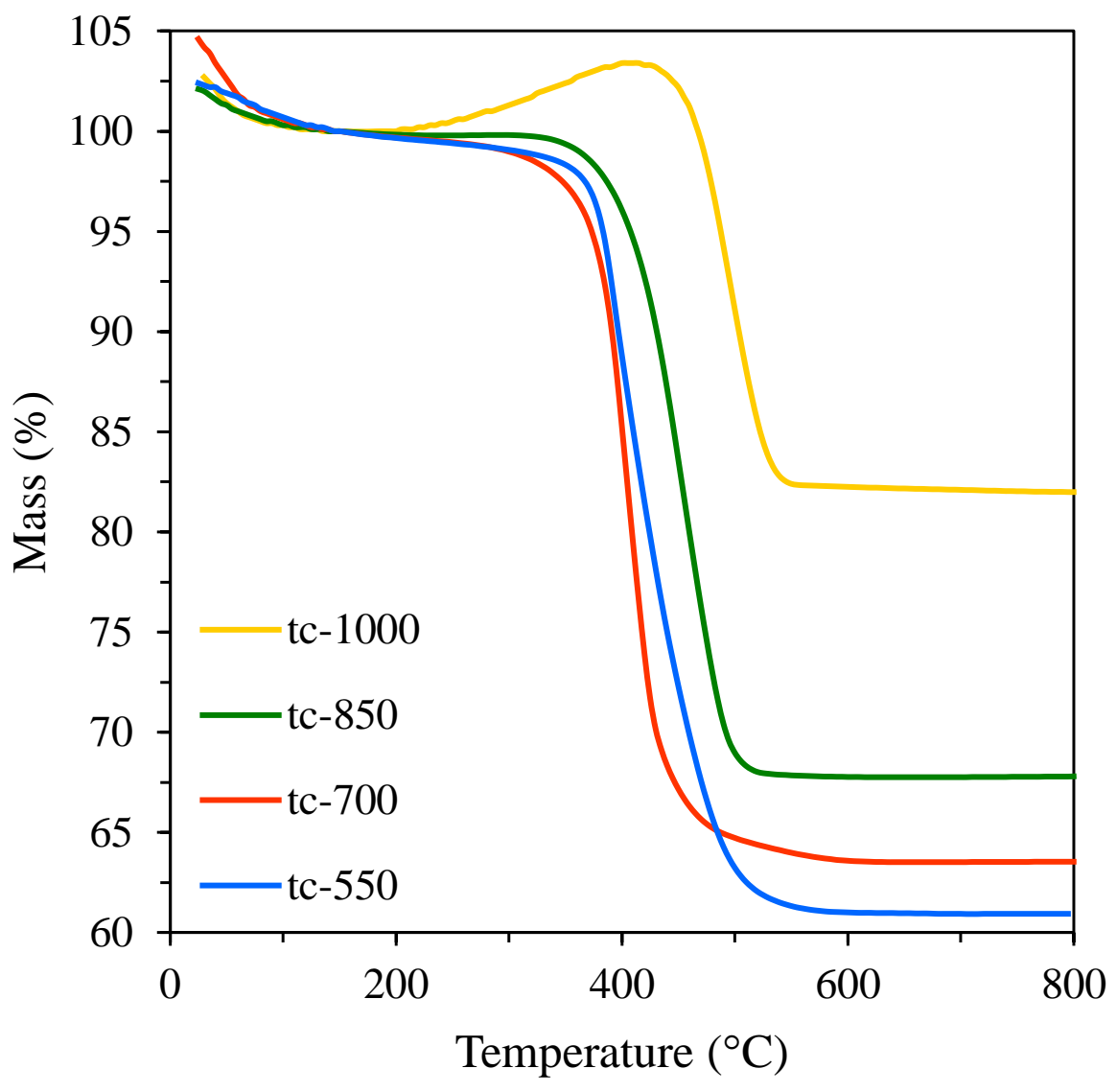

Figure S2. Thermogravimetric curves for the carbon-titania composites prepared from $\mathrm{Ti}(\mathrm{citr})_{3}$. Each TG run was done in air. $100 \%$ mass is set for the outgassed sample, i.e., at $150{ }^{\circ} \mathrm{C}$. 


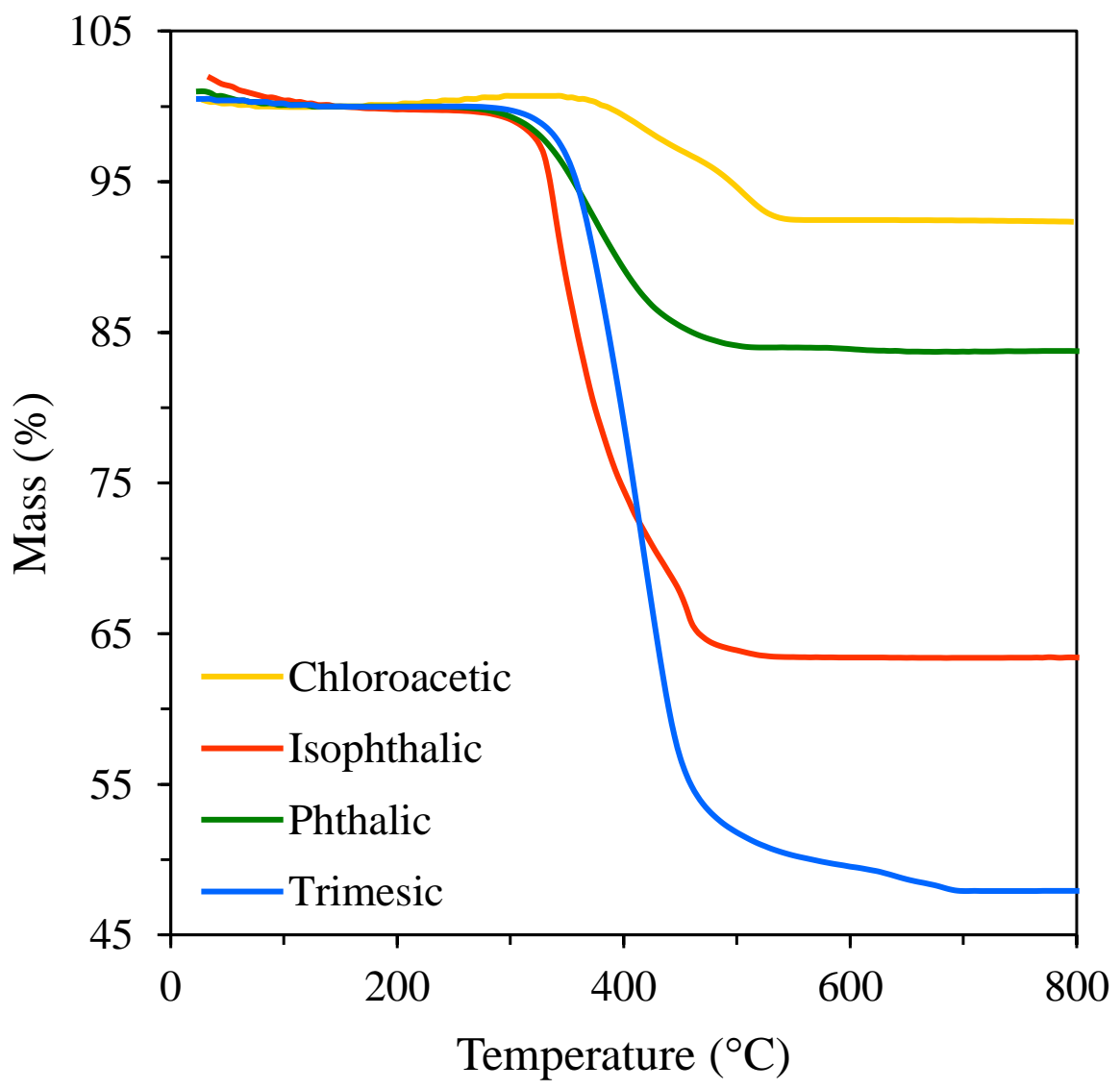

Figure S3. Thermogravimetric curves for the carbon-titania composites prepared from TIPO modified with: chloroacetic, phthalic, isophthalic, and trimesic acid. Each TG run was done in air. $100 \%$ mass is set for the outgassed sample, i.e., at $150{ }^{\circ} \mathrm{C}$. 

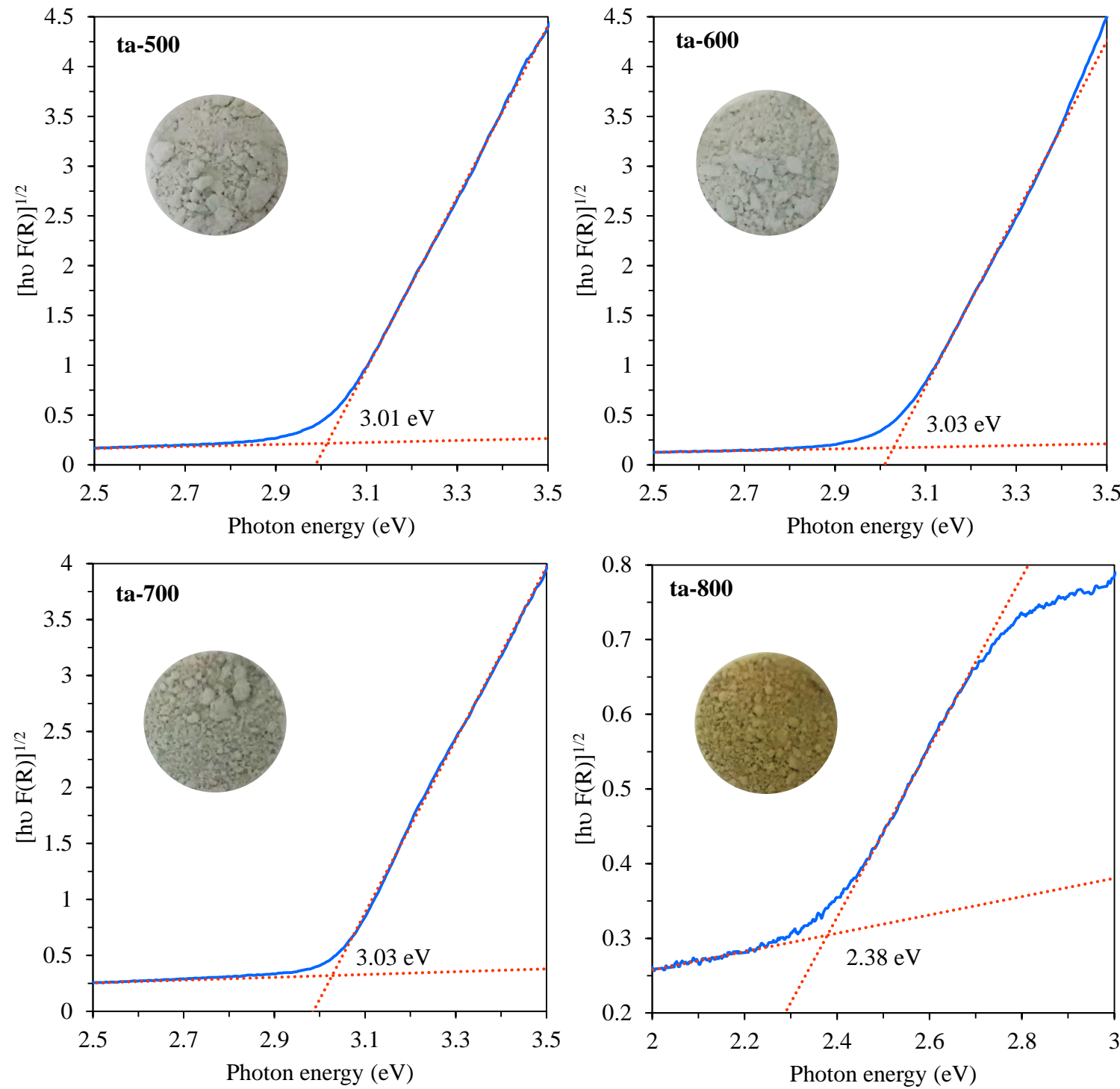

Figure S4. Tauc plots of $[h v F(R)]^{1 / 2}$ vs. hu used to calculate band gap values for the titania materials prepared from $\mathrm{TiO}(\mathrm{acac})_{2} . \mathrm{h}$ is the Planck constant, $\mathrm{v}$ is light's frequency, and $\mathrm{F}(\mathrm{R})$ is the Kubelka-Munk function calculated as $F(R)=(1-R) / 2 R$. 

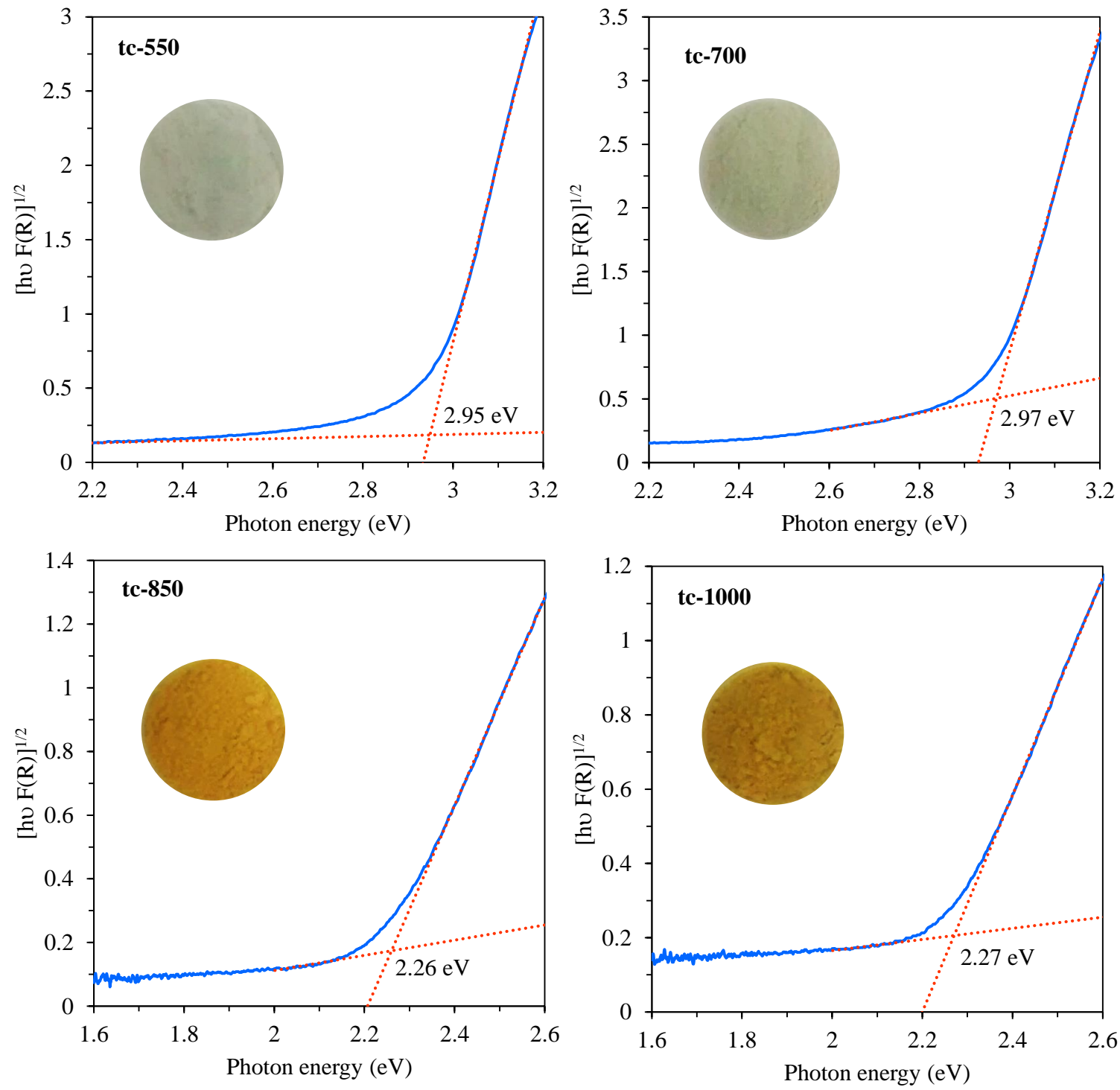

Figure S5. Tauc plots of $[h v F(R)]^{1 / 2}$ vs. hu used to calculate band gap values for the titania materials prepared from Ti(citr $)_{3} . h$ is the Planck constant, $v$ is light's frequency, and $F(R)$ is the Kubelka-Munk function calculated as $F(R)=(1-R) / 2 R$. 

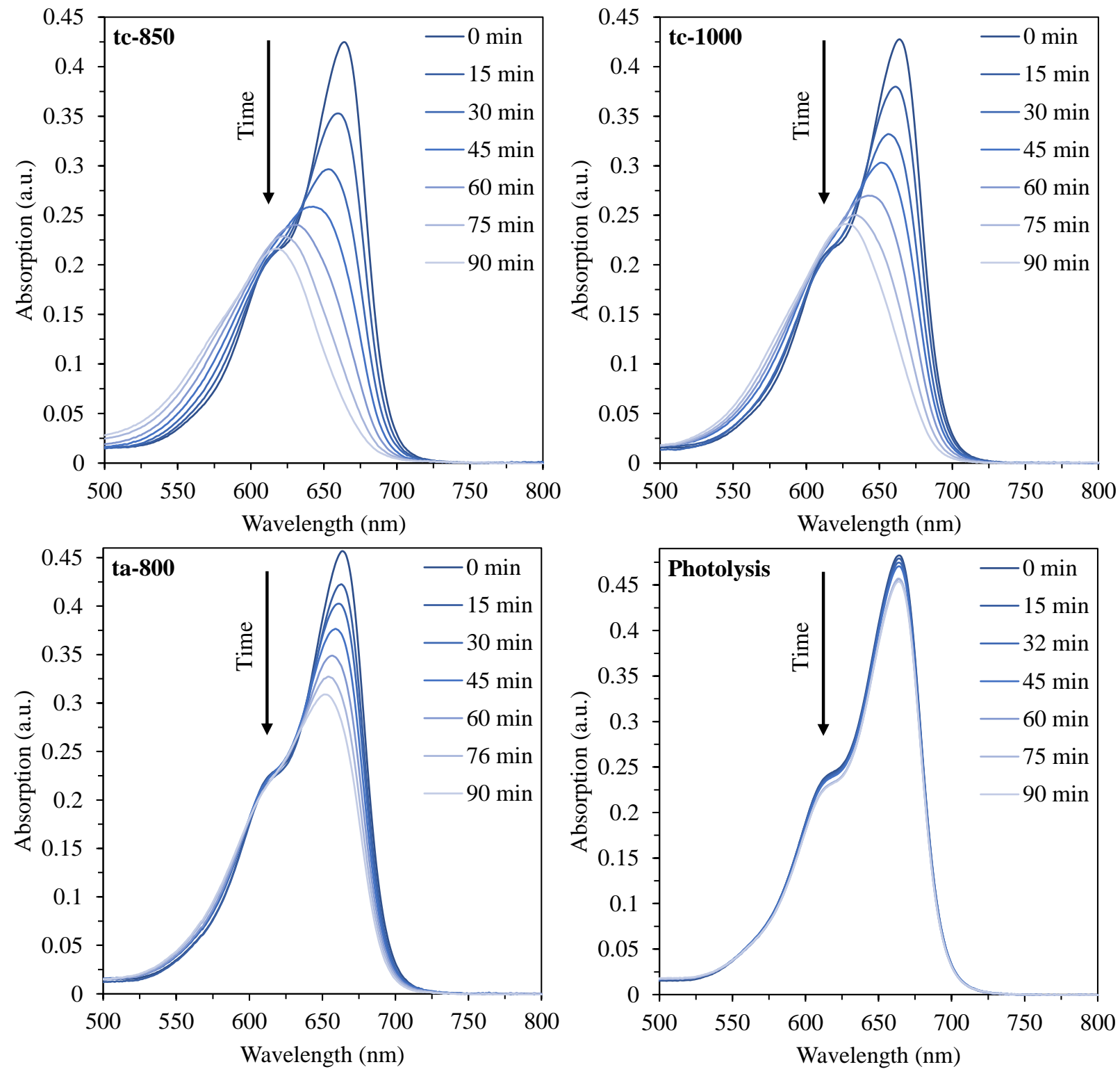

Figure S6. Scattering-corrected UV-Vis absorption spectra of methylene blue during photocatalytic degradation in the presence of tc-850 (left top), tc-1000 (right top), ta-800 (left bottom), and blank (right bottom). 

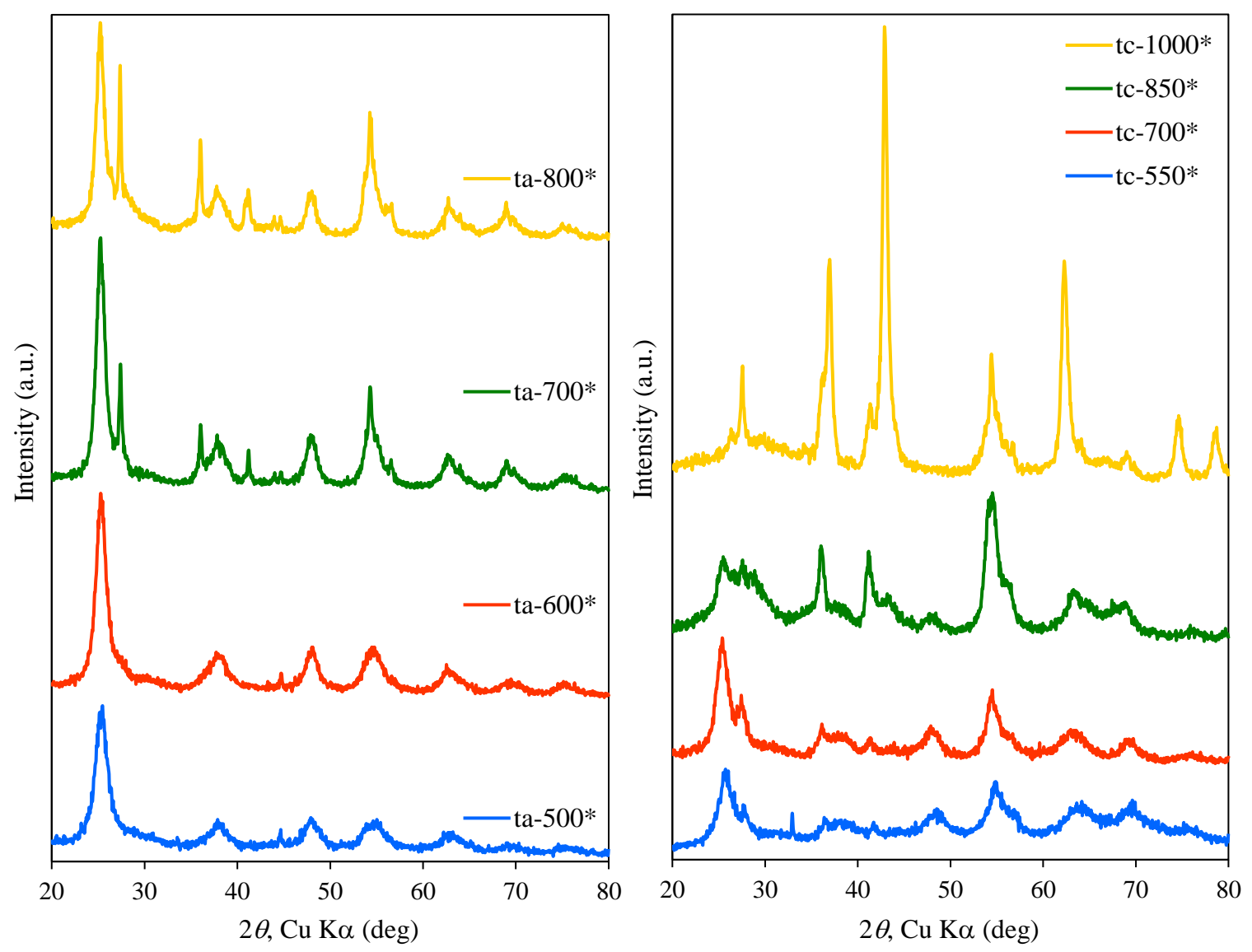

Figure S7. Powder X-ray diffractograms for the carbon-titania composites prepared from $\mathrm{TiO}(\mathrm{acac})_{2}$ (left) and $\mathrm{Ti}(\mathrm{citr})_{3}$ (right). ta-600*, ta-700*, ta-800*, tc-550*, tc-700*, and tc- $1000^{*}$ diffractograms shifted up for clarity. 


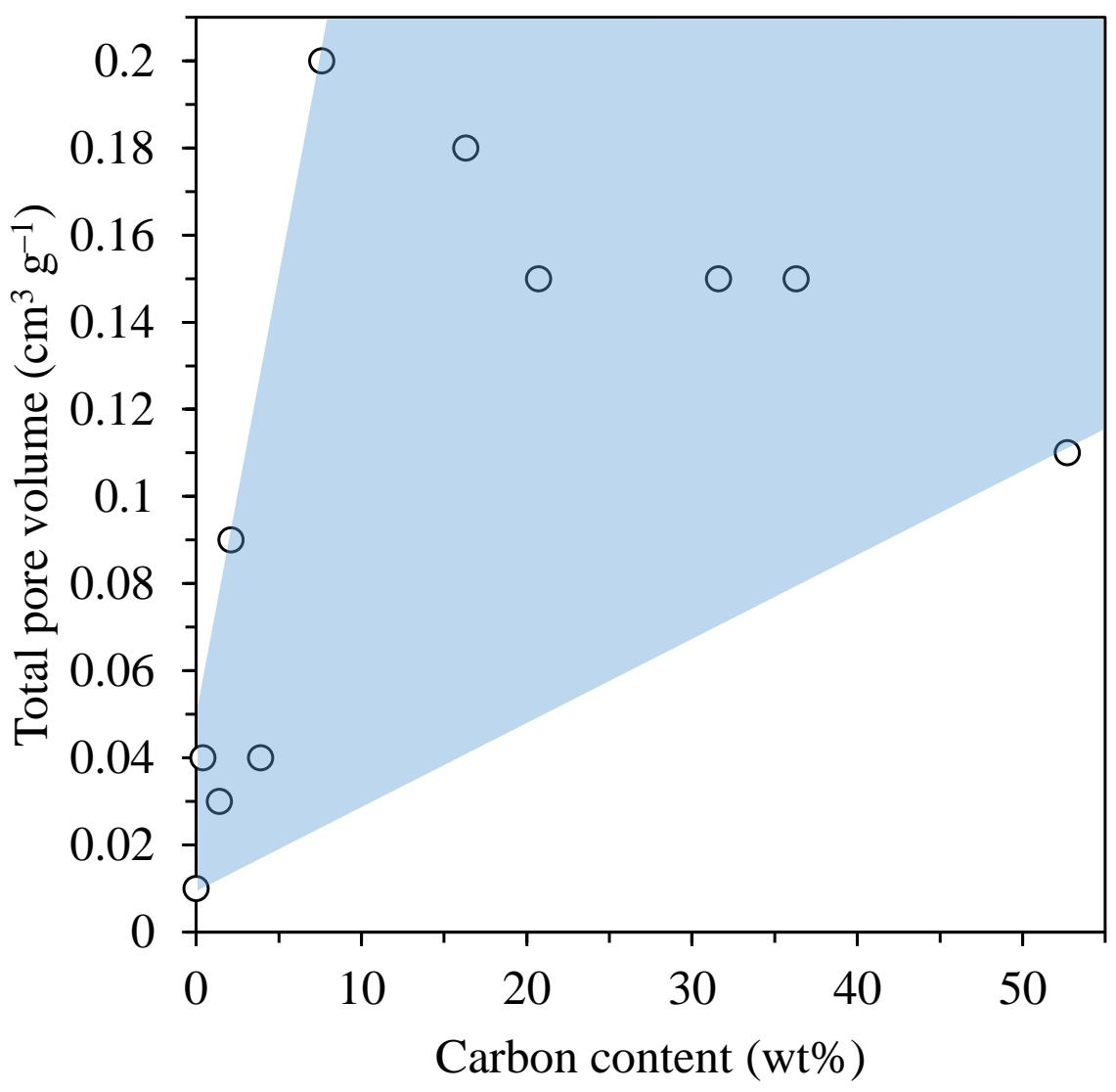

Figure S8. Total pore volume as a function of the carbon content for the materials prepared from TIPO modified with: formic, acetic, chloroacetic, oxalic, benzoic, phthalic, isophthalic, and trimesic acid. ta-800, tc-850, and TIPO included for reference. 

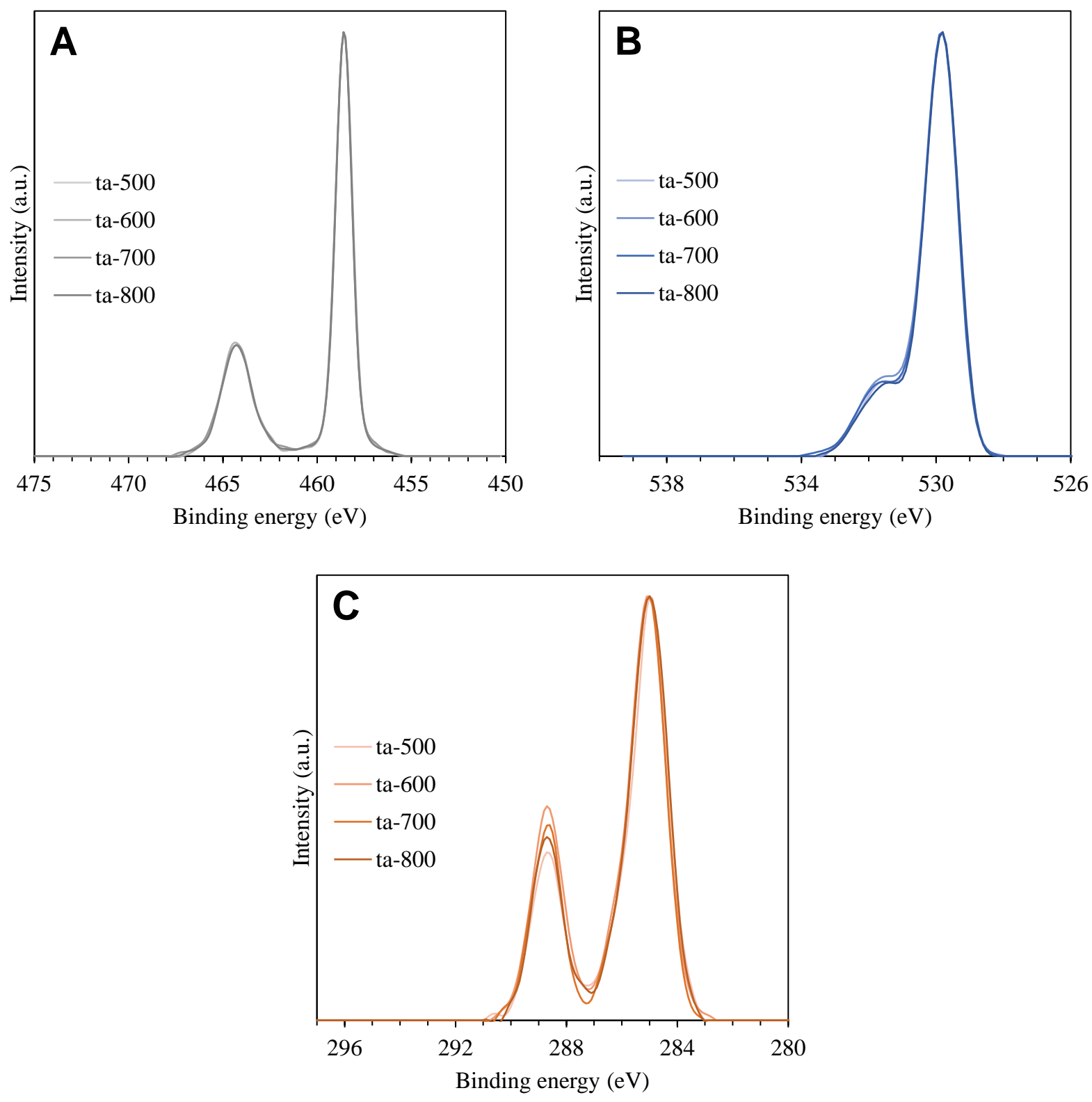

Figure S9. High-resolution X-ray photoelectron spectra for the ta series: A) Ti 2p, B) O 1s, and C) C $1 \mathrm{~s}$. 

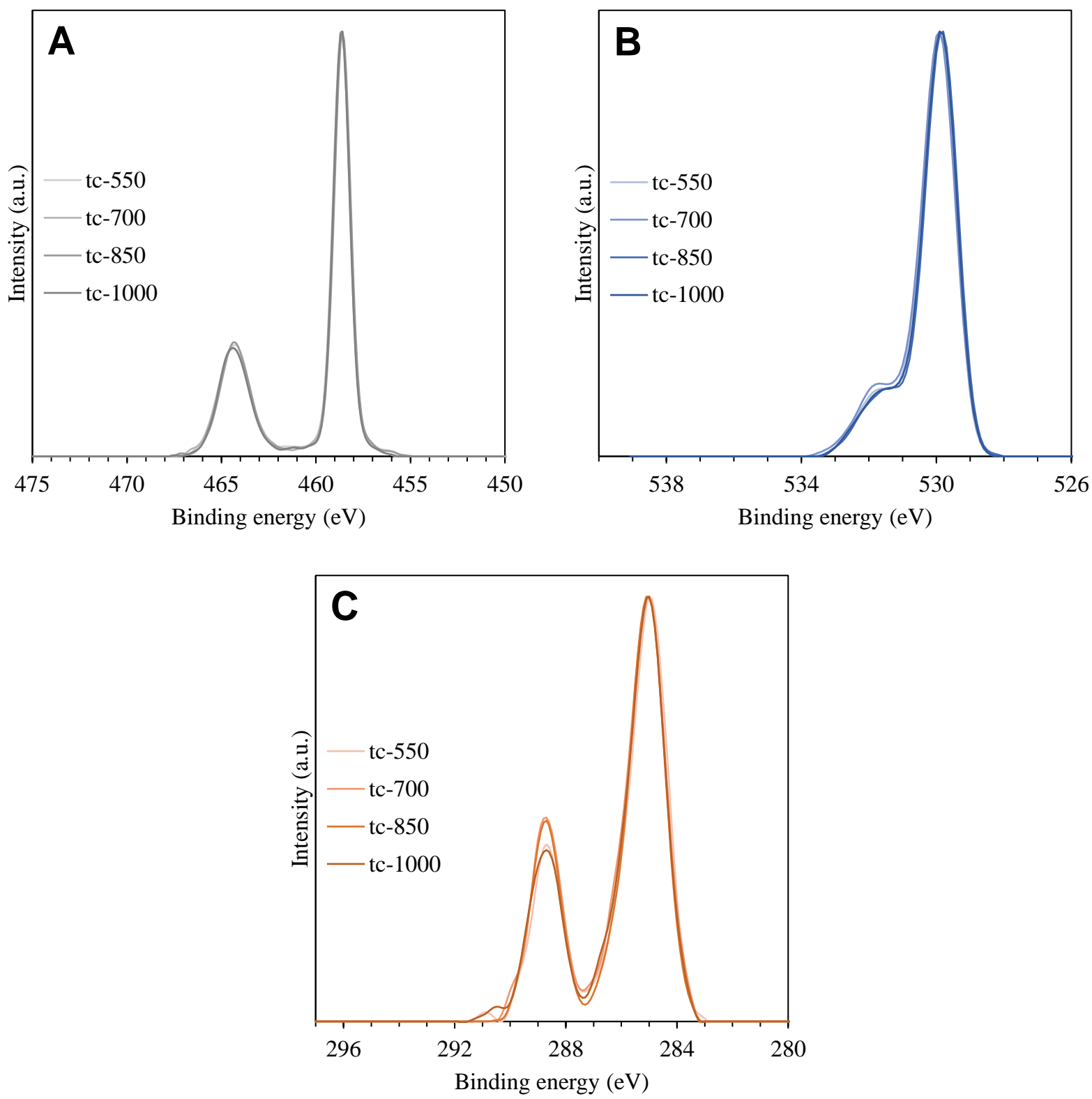

Figure S10. High-resolution X-ray photoelectron spectra for the tc series: A) Ti 2p, B) O 1s, and C) C $1 \mathrm{~s}$. 


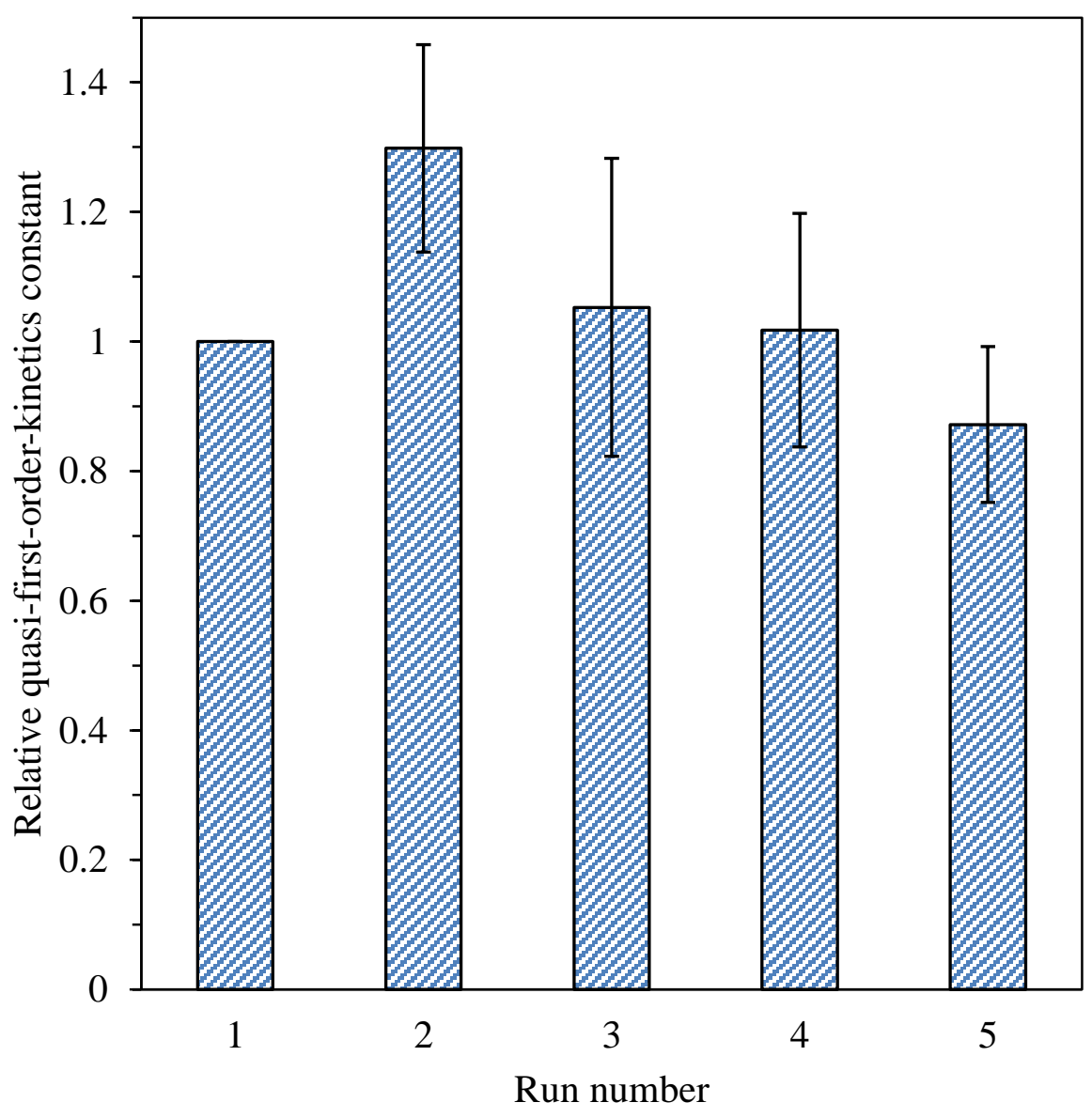

Figure S11. Loss of photocatalytic activity as a function of run number. Relative quasi-firstorder-kinetics constant was calculated as a ratio of the constant at the $\mathrm{n}^{\text {th }}$ run and the constant at the first run. 